\title{
KNOWING WHAT I HAVE DONE
}

\author{
MatTHias HaASE \\ University of Chicago \\ Department of Philosophy \\ 1115 E. 58th St. Chicago, IL 60637 \\ Chicago, Illinois IL 60615 \\ U.S.A. \\ haase@uchicago.edu \\ matthaase@gmx.de
}

\author{
Article info \\ CDD: 121

\section{Keywords: \\ Practical knowledge \\ Intentional action \\ Action and time \\ Anscombe}

Received: 13.09.2018; Accepted: 21.09.2018

DOI: http://dx.doi.org/10.1590/0100-6045.2018.V41N4.MH

\begin{abstract}
The literature on agentive or practical knowledge tends to be focused on knowing what one is doing or what one is going to do. Knowing what one has done and has achieved thereby seems to be another matter. In fact, achievements are often taken to be beyond the ken of practical knowledge. I argue that this is a mistake. The intelligibility of the very idea of practical knowledge depends on the possibility of knowing one's achievements in the same manner. For if it is to be intelligible as knowledge of the actuality of one's action in the material world, knowing what one is doing has to include knowledge of what one has done so far.
\end{abstract}




\section{TWO WAYS OF KNOWING ONE DEED}

Recognizing what one has done can come as a shock. So it did for Oedipus: "Oh gods no!", he cried out, "I think I've cursed myself, called down calamity. I never knew." That this sort of thing can happen, even to the best of us, is the topic of Sophocles' tragedy. But, of course, it wouldn't be tragic, if that was the only kind of relation in which one can stand to what one has done. Indeed, that he cursed the murderer of Laius did not come as a surprise to Oedipus. According to his original conception, that act belonged, as it were, to his résumé as a responsible ruler of the city. That thought about his action he could have voiced like this: "Here is my work, the actuality of my agency. That is the kind of man I am."

Both statements purport to express knowledge: a discovery about the deed and agentive knowledge of the work. I want to suggest that the difference between such bits of knowledge is not just a matter of the object known, but also concerns the manner in which it is known. In the fundamental case, knowledge of one's work or achievement is a distinct form of cognition that has been neglected in contemporary action theory. In the recent literature on agentive or practical knowledge, the focus tends to be on knowing what one is doing and what one is going to do. Knowing what one has done and has achieved thereby is rarely considered in this context. And when it is, then usually as a secondary phenomenon, derivative to the case where the action is present, alive as current doing, rather than dead and done with. This, it seems to me, is a grave error. The neglected past will haunt the accounts of present practical consciousness. Unless what has been done so far is originally within its ken, agency won't be for the agent at all. Yet, it doesn't seem to fit into the proposed models of agentive or

1 Sophocles Oedipus Tyrannus, 744-745. 
practical knowledge. In consequence, the 'I do' will appear like a mere illusion. Or so I shall argue.

Oedipus' calamity is instructive for this purpose. On the one hand, it illustrates the contrast between the two ways of recognizing what one has done. On the other hand, it exhibits the very aspect of the human condition that makes it tempting to think that ultimately there can only be one way of knowing what one did.

Sophocles' staging of the story is famously a multifaceted play on the vexed reflexive that sets those two descriptions of Oedipus' action apart. The murder of Laius was all along his deed. So all along he talked about himself when he talked about Laius' murderer. But not, so to speak, as himself. For him it was the deed of another. Until he made the connection and came to see, in the terms of Geach's and Castañeda's notations, that he himself or he* was the one who did it. ${ }^{2}$ Yet, at the same time, it remained alien or other. Once he did find out what unspeakable deeds he had to call his own, he could not see himself in them. And the reason why he couldn't was precisely that he didn't do them in that sense. Still, the discovery alienated him from what he did do in that sense in which a philosopher might say that the act was emphatically 'his own' and thus 'for him as his* act in its performance.' For he saw that they are the same. In the face of what he found out about it, he could not hold on to his original vision of his work. That was so unbearable that he took his own eyes muttering, "You may not see the evil, not the evil I have done - or suffered." 3

This may be deemed an unnecessary confusing way of putting it. After all, what happened was basically this: Oedipus intentionally killed a man by whom he felt threatened and later married a woman of his liking. That man

2 See Geach 1957 and Castañeda 1966.

3 Sophocles, Oedipus Tyrannus, 1271-1272. 
was his father and that woman his mother. But these characterizations of his victim and his bride don't belong to the description under which his actions were intentional. To the contrary: what brought him to those crossroads was precisely his intentionally leaving behind those whom he took to be his parents. Setting the scandalous details aside, that doubleness of his deed exemplifies a general feature of the human condition, an inescapable aspect of what agency is like for the kind of creatures we are. It is always possible that what under one description a person did intentionally and perhaps with the best intentions is under another description something that is in fact contrary to her will. When that happens, it is quite unfortunate of course. And hard to come to terms with in practice. But one might think that, philosophically speaking, there is nothing confusing here. The adverb 'intentionally' creates an intensional context. That is all. The rest is literature.

On closer inspection, it can't be quite like that. Any old vital description creates an intensional context. ${ }^{4}$ Yet, traditionally speaking, there is no place for tragedy in the life of plants or brutes. And that is because their 'agency' isn't ever 'for them' in the relevant sense. They never see themselves in what they have done, at least not in that way that is connected with possibility of despairing over it. Tragedy is a possibility only in the kind of living that is subject to choice and deliberation. As Aristotle famously presents it, tragedy induces "pity and fear in all of us", because the hero who falls into misery was acting on a (more or less) sound conception of how to live. Oedipus' fall is not a consequence of a "depravity of character", but rather due

4 The mouse that the cat is hunting may belong to Smith. And this bit of Boston Ivy is entwining around a pillar of Emerson Hall. But these aspects of the prey and ground don't belong to the perspective of the vital description in terms of 'hunting' and 'entwining' or 'growing.' 
to a "great error on his part." 5 It's on him, because he did it. But it is undeserved, because he couldn't have known. The universal possibility of such mishaps reveals the limitation or finitude of our power of practical reason. The philosophical difficulty is how to conceive of that limitation without losing the idea that reason in its practical deployment is a power that is realized in changing objects in the world.

In a paper on Aristotle's account of tragedy, Aryeh Kosman draws the line separating those two aspects of agency that constitute the doubleness of the deed in the following way:

"On the one hand, an action is the object of the intentional states of a deliberative and choosing agent: it is what we do in the sense that it is what we are about and what we take ourselves to be doing. On the other hand, however, an act is what we do in the sense of what emerges as the result of our activity. What is revealed in tragedy is the ever-present possibility of a fracture between these two aspects of action. Tragic lives figure the chance of a rift between actions understood as the expressions of the character and intentional choices of moral agents and actions as events in an objective world outside the control of such agents, actions with lives of their own which thus transcend the intentions and plans of their authors." 6

The thought that actions considered as "events in the objective world" are "outside of [the agent's] control" and

5 See Aristotle, Poetics, 1453a16.

6 Kosman 2014, p. 113.

Manuscrito - Rev. Int. Fil. Campinas, v. 41, n. 4, pp. 195-253, Oct-Dec. 2018. 
have "lives of their own" seems to suggest that the aspect of our agency that is properly under agentive control is limited to action considered as an "expression of [...] choice." But since such "expressions" may be thought to be "events in the objective world" as well, perhaps it is, strictly speaking, just the act of choosing. ${ }^{7}$ In the resulting picture it looks like whether we actually did in the end what we took ourselves to be doing is something that can only be known in one way: we move our wills, and perhaps our bodies, as well as we can, what comes of it remains to be seen.

It seems to me that this can't be what Aristotle had in mind. In any case, it would appear to be in tension with his characterization of techne and phronesis - knowing how to make something and knowing to act well - as forms of cognition that are essentially productive and whose exercise reaches all the way to what Kosman calls the "objective world." That is, into material reality outside the limits of the agent's body. Say, the house that comes to be and the good praxis of living together of which it is a part. In this connection, it seems worth noting that there is an aspect of Aristotle's discussion of tragedy that brings the contrast between those two ways of knowing what one has done back into view. One of the proper forms of tragedy, Aristotle says, is the one where "the deed [is] done in ignorance, and the relationship discovered afterwards." 8 And he praises Sophocles' Oedipus as a perfection of this form, since it makes the process of discovery the center of the piece.

7 A footnote in the vicinity suggests a possible extension of the sphere of agentive control. There Kosman presents his consideration as a "meditation" on Donald Davidson's thesis that "[w]e never do more than move our bodies: the rest is up to nature." (See Davidson, 1971, p. 59 and Kosman, 2014, FN 28, p. 306.)

8 Aristotle, Poetics, 1454a3-4.

Manuscrito - Rev. Int. Fil. Campinas, v. 41, n. 4, pp. 195-253, Oct-Dec. 2018. 
The plot is devoted to Oedipus' epistemic endeavor to find out what $h e^{*}$ did. He insists on getting all the evidence: "Make it known! Everything must be exposed." In the end, he knows that $h e^{*}$ killed $h i s^{*}$ father and married $h i s^{*}$ mother. And the manner in which he knows it rests on evidence. It is knowledge by hearsay and inference. But that this was something that could be learned through the particular kind of inquiry Oedipus was engaged in requires that other descriptions of his actions were already available to him. That he killed a man on the road and married a woman named Jocasta - these things he did not have to find out in the course of the play. He knew all along. That is presupposed on every page. In every question he asks his interlocutors. And there is no indication that we are supposed to assume that the latter knowledge is due to some prior investigation, another collecting of evidence that happened before the course of events that make up the plot. To the contrary, everything suggests that the peculiar cascade of the reflexive that characterizes the kind of learning process we are witnessing is to be seen against the background of another manner of knowing what one has done. For, the discovery at the end is only shocking, because it concerns what he all along knew to be his work. How, then, does he know, if not by evidence? We are not told in the play. That question seems to be left for the philosopher to answer. But it doesn't seem to have been taken up by contemporary action theory.

\section{THE TWO LINES OF ANALYTIC ACTION THEORY}

Incidentally, the verbs describing Oedipus' two tragic misdeeds are prominent examples in the contemporary philosophy of action. They seem to point in opposite

9 Sophocles, Oedipus Tyrannus, 1050. 
directions. According to conventional wisdom, one can't get married without knowing. 'Smith killed Jones', by contrast, is compatible with Smith leaving the scene in ignorance about whether the act is to be counted among the killings or just the attempts on a life. The two main strands of analytic action theory are divided over the question which of those two scenarios is to be taken as the paradigmatic case.

According to the one, the light of the wedding party shines, as it were, throughout the whole domain of the intentional. G.E.M. Anscombe famously lists 'marrying' among the action verbs that she takes to provide the central clue for the philosophical treatment of human agency. Like 'telephoning', 'greeting', 'groping' and 'signing', it describes something that can only be done intentionally. Focusing on such cases is supposed to enable us to see that the term 'intentional' refers to "a form of description of events." 10 And that form is supposed to be characterized by the knowledge that the agent has of her performance. In one aspect, all human intentional action is like marrying: action in progress is intentional under a description only if it is known to the agent under that description. In Anscombe's own words: “it is the agent's knowledge of what he is doing that gives the descriptions under which what is going on is the execution of an intention. [...] without [the agent's knowledge] what happens does not come under the description - execution of intentions." (Anscombe, 2000, \$48)

The other strand of action theory takes, as it were, the opposite approach. Its focus is on killing. Poisoning in particular, since it shows how far the "basic" thing the agent does can be removed from its intended results: "She has done her work; it only remains for the poison to do its," Davidson says in a crucial passage of the essay that he takes

10 See Anscombe, 2000, \47. 
to provide a "vast simplification of the problem of agency."11 That "vast simplification" is the thesis that all action collapses into a "primitive" action. Everything else is just further descriptions of it that take its causal effects into account. An implication of the operation is that the agent's knowledge of the actual occurrence of those effects is irrelevant to the question whether they can figure in the content of the description under which her action is intentional. And Davidson maintains that it makes no difference to this point whether the relevant effects are removed in time, as is death in the case of a slow working poison, or in space like, for instance, the graphic marks occurring on the papers further down in a stack of carbon copies that the agent is trying to sign all in one go by writing his name on the top sheet. Davidson concludes that Anscombe's conditional is false: "It is a mistake to suppose that if an agent is doing something intentionally, he must know that he is doing it." (Davidson, 1978, p. 91) All that the man with the pen has to know is that he is "trying."

The scenario that sets up the famous carbon copy case seems designed to cast the shadow of death even onto the domain of the conventional. ${ }^{12}$ In any case, Davidson insists

11 See Davidson, 1971, p. 58 and p. 61.

12 We are asked to imagine a man bequeathing his fortune to his children in order to provide for their welfare. He dies before knowing whether it worked. Still Davidson insists that if bequeathing his fortune to them leads to their welfare, then the man can be said to have intentionally provided for their welfare. Why, then, shouldn't it be the same with the former? Let it be an essential part of the wedding ceremony to sign a marriage contract. And let the groom be blind. Now he is moving pen over the document. The next moment 'tragedy' strikes: he dies before anyone could tell him that the pen worked. Who is to say that he didn't leave a widower? A similar fate awaited the version of the knowledge requirement that the original presentation of the doctrine left intact. Davidson maintains that intentional action in 
that the inference from 'doing intentionally' to 'doing knowingly' is not valid tout court. Accordingly, it is hopeless to try to delineate the domain of the intentional by appeal to the agent's knowledge of her performance.

These different views on the question of what role the agent's knowledge has to play in an account of intentional action go together with two opposed conceptions of the character of such knowing. Davidson says little about the latter topic. But it is usually taken to be in the spirit of his teachings to conclude that there is not much to it. Accordingly, the agent's epistemic relation to the descriptions under which her actions are intentional is, in principal, like Oedipus' relation to those unspeakable deeds he had to call his own in the end. Not that it all comes as a shock. And the knowledge is always taken to be acquired after the deed is done. But it is a common view that knowing that one is actually doing what one intends must rest on evidence. It derives from perception, hearsay or inference. What this comes to exactly varies according to the theory at hand. ${ }^{13}$ Whether or not action is thought to be given to outer

the present is always known to the agent under some description not in terms of doing something to an object different from oneself, but in terms of moving one's body "in just the way required." (See Davidson, 1971, pp. 50-51.) On the face of it, however, it looks like his own medicine, if it is effective, should purify the teaching and sweep away the last trace of Anscombian doctrine. If knowledge of attempt is sufficient with respect to to the pen and the paper, why should it be any different with respect to the hand? Indeed, scenarios parallel to the carbon copy case have been presented to suggest this conclusion. (See, for instance, Setiya, 2008, p. 390).

13 Where the intention is taken to be known in a special way, one might call the resulting picture a "two factor view" of agentive knowledge. (The term is from Falvey, 2000). With respect to the action, some say that you have to perceive it. (See, for instance, Donnellan, 1963). Others think you can infer it from the intention 
or inner sense, I shall assemble all of these views under the heading of Evidentialism about agentive knowledge.

Anscombe, by contrast, maintains that the agent's epistemic perspective on her own intentional action is of a fundamentally different kind than that of a spectator. They are two ways of knowing one and the same object: from without and from within, "by observation" and "without observation." In her final account, the merely negative characterization as "non-observational" is replaced by the appeal to Aquinas' formula according to which "practical knowledge is the cause of what it understands." Such cognition differs from its theoretical counterpart by the way in which it is related to its object. Whereas the latter is derived from the reality of its object, the former is productive of it. ${ }^{14}$

\section{THE CONVERGENCE IN THE ACCOUNT OF THE DEED}

Despite their rather different trajectories, the two lines of action theory seem to converge in the account of the deed. In the very section in which Anscombe introduces Aquinas'

- given experiential knowledge of the connection between intention and action. (See, for instance, Paul, 2009). A third approach suggests that in the normal case, the agent experiences her intentional action directly by a special "sense of agency", a how-it-feels-to-act-intentionally. (For a helpful overview of the different versions of this approach see Siegel, 2005).

14 See Anscombe, 2000, \$48. Anscombe insists that the scope of such practical cognition is not restricted to mere bodily movement. When one is pushing a boat or opening a window, one's knowledge from within reaches all the way to the objective world: the things one is working on, the boat that is being pushed and the window that is being opened. See Anscombe, 2000, $\$ \$ 29-30$. On the latter point see also Ford, 2018. 
formula, it looks like the agent's achievements fall on the other side of her divide between the two ways of knowing:
"Normally someone doing or directing anything makes use of his senses, or of reports given to him, the whole time: he will not go on to the next order, for example, until he knows that the preceding one has been executed or, if he is the operator, his senses inform him of what is going on. This knowledge is of course always 'speculative' as opposed to 'practical'." (Anscombe, 2000, \$48)

The passage seems to suggest that, in contrast to knowing what one is doing, knowledge of what one did or has done is always theoretical rather than practical. ${ }^{15}$ Given a certain rendering of Aquinas' formula, this seems inevitable. What is done is in the past. And it would seem that a present state of mind can't be the cause of what happened already. The consequence seems to be that, epistemically speaking, the agent stands to her work or achievements in the same way as

15 The formulation in the passage is compatible with the thesis that there is a further way of knowing one's achievements - in addition to what seems to be described in the passage as the "normal" case. However, such an alternative manner of knowing one's achievements is not mentioned in the remainder of the section that is supposed to present her final view on the matter. Since Anscombe's Intention is not an easy read, pretty much every line can give rise to a debate about whether she really meant it or, in any case, should have said it. It is the same here. There are readings that imply that the passage just quoted would have to be either understood in a different way or disregarded as misleading. (See $\$ 5$ below.) In this paper, I am not primarily concerned with settling the scholarly issue about Anscombe interpretation. Whether or not the thought sketched is ultimately her view, it has been very influential in the literature. 
a spectator would. When it comes to what is done, there appears to be only one way of knowing. But the done deed is precisely what was on Oedipus' mind. And the plot appears to turn on the contrast between two ways of knowing what one has done.

Anscombe's exclusion of the perfective from the ken of practical knowledge seems to be foreshadowed by what is commonly taken to be her first positive characterization of the kind of cognition she later elucidates by appeal to Aquinas' formula. Earlier on in the book, the knowledge that an agent has of her intentional actions is presented under the heading of "knowledge in intention."16 Given the two guises in which intending can appear - in action and prior to action the formulation puts the spotlight on knowing what one is doing and knowing what one is going to do. Knowing what one has done seems to be another matter. And it tends not to come up in the recent literature on practical knowledge. The main division in that debate is over the question which one of the other two should be treated as its paradigmatic object: action currently under way or action yet to come. ${ }^{17}$

The peculiar neglect of the mission accomplished has to do with the way Anscombe approaches the topic of agentive or project knowledge. The project of Intention is to delineate the class of intentional actions by reflection on the special kind of knowledge that an agent has of her intentional

16 See Anscombe, 2000, \$32. Since the phrase belongs to Anscombe's preliminary remarks on the matter, its status in her ultimate doctrine is, once again, disputable. But usually it is taken for granted that this is a proper characterization of practical knowledge of concrete action.

17 Since it seems to introduce a further topic that doesn't seem immediately salient to the question at hand, I postpone the discussion of the latter approach to $\$ 6$ below. 
actions. ${ }^{18}$ This requires finding for all descriptions under which action is intentional a form of representation that abides by something akin to the special rules that, according to conventional wisdom, govern the use of concepts like marrying. That would obviously be a hopeless endeavor fated to drown in a flood of counterexamples, if it weren't for a certain take on the temporality of human agency that doesn't really come into focus in Davidson's approach.

Notoriously, a wedding can get interrupted. The traditional form of the ceremony even marks a place for interference by the audience. Alternatively, one of the parties might change her mind in the last moment. Or perhaps a flood carries away the whole party before the union for life is made. It is different in the case of killing. Unless someone is dead at the end, there wasn't any killing in the literal sense of the word. This contrast is marked in the grammar of English. Just like 'to build a house', 'to cross the street' or 'to clench a fist', 'marrying' is a telic action verb that is predicated under the aspectual contrast. Whereas the progressive or imperfective ' $S$ is/was $\phi$-ing' describes progress under way, the correlated perfective ' $S$-ed' describes completion achieved. Since interruption is possible at any point, past progressive ' $S$ was $\phi$-ing' doesn't entail the perfective ' $S \phi$-ed.' The verb 'killing' or 'finishing someone', by contrast, belongs together with 'winning', 'arriving' or the generic 'finishing something' to what Gilbert Ryle calls achievement verbs. They imply 'success' in the sense of perfection or completion.

In Davidson's approach, the difference between these two kinds of action verbs doesn't play much of a role. The focus tends to be on action sentences in the perfective. ${ }^{19}$

18 See Anscombe, 2000, $\$ 8$.

19 See Davidson 1967. It is not that Davidson would deny that there is a difference. But the suggestion seems to be that the 
And for all he says in the paper that is supposed to provide the "vast simplification of the problem of agency", the "basic" or "primitive" action may as well be an instantaneous act that can only be described by achievement verbs. Anscombe, by contrast, shares Ryle's view of the derivative or secondary status of achievement verbs. Ryle insists that "achievements" are "not acts, exertions, operations or performances, but, with reservations for purely lucky achievements, the fact that certain acts, operations, exertions or performances have had certain results." (Ryle, 1984, p. 151) On closer inspection, achievement verbs don't signify instantaneous actions performed at a single moment; they describe, as Anscombe puts it, "the terminus of something that takes time." (Anscombe, 1981, p. 191) Verbs like 'arriving' or 'finishing' capture completion achieved through progress described by a different action verb. Not everyone who participates in the race wins. But unless it's cheating or a mere stroke of luck, victory can come through nothing but racing. Similarly, not every crossing ends with arriving. However, Ryle's dictum holds: "When a person is described as having journeyed and arrived, he is not being said to have done two things, but to have done one thing with a certain upshot." (Ryle, 1984, p.

proposed analysis of action sentences in the perfective can easily extended to encompass a correlated account of the imperfective. Broadly speaking, there are two ways in which one may try to introduce the temporality of human agency into the Davidsonian framework. Bratman (1987) proposes to introduce temporal agency through the idea of higher order planning structures. According to this view, the basic building blocks of those temporally extended actions may themselves not be point-like or instantaneous, at least not within the practical perspective. Alternatively, Parsons (1990) tries to introduce the temporality on the basic level by showing how the aspectual contrast can be treated within a broadly Davidsonian treatment of the logical form of action sentences. For a critical discussion of the former strategy see Lavin 2013. 
150) If it is to be true that I crossed the street, my being on the other side must be the result of activity that was properly described by the correlated imperfective as long as it was present.

Achievement verbs are the lexicalized version of the expressions of the perfective aspect. And it is only through reflection on descriptions in terms of ordinary telic action verbs to which the aspectual contrast applies that the very idea of an agentive or skillful rather than merely lucky achievement becomes intelligible. Without reflection on the imperfective there can be no account of intentional movement. That is, of course, Aristotle's point: "every movement involves time, and relates to some goal, as does e.g. the movement that is building, and it is complete when it finally does what it aims at." ${ }^{20}$ Anscombe's project to explain the concept intentional by appeal to a "form of description of events" that is characterized by the special kind of knowledge that the agent has of her performance rests on Aristotle's point. Her thesis that an action is intentional under a description only if it is known to the agent under that description is stated in the progressive. It would obviously be ludicrous to make the agent's knowledge of completion or perfection a general condition for the truth of a statement about her having $\phi$-ed intentionally. One might as well try to defend oneself against a murder charge by arguing that one didn't know of one's success at the time of reaching it.

Michael Thompson argues that further reflection on the temporality of action in progress provides a treatment of the counterexamples that inevitably spring to mind. Once one notices the logical features of the progressive, it turns out that Davidson's carbon copy case passes Anscombe by: It can be true that a subject is in the process of signing ten

20 Aristotle, Nicomachean Ethics, 1174a20. 
carbon copies and knowingly so, even though right at this moment letters are only appearing on the top three..$^{21}$ This allows us, Thompson argues, to hold on to what earlier on the paper presented as Anscombe's "real definition" of the concept of intentional action "in terms of a form of selfknowledge": "what's up with me is an intentional action precisely where it is a content of specifically practical knowledge, otherwise not." (Thompson, 2011, 203) In the course of setting up this response to Davidson's objection, Thompson also determines the possible scope of that manner of knowing. As Thompson presents it, Anscombian practical knowledge is in action and for this reason restricted to progression. Completion or perfection can never be within its ken:

"The content of Anscombe's practical knowledge is progressive, imperfective, in medias res. [...] there is practical knowledge only when the thing is precisely NOT done, not PAST; there is more to come, something is missing, and the H-bomb may hit before it does." (Thompson, 2011, p. 209)

The argument that Thompson presents on Anscombe's behalf proceeds from the premise that practical knowledge is a kind of "self-consciousness" and can thus be compared

21 See Thompson, 2011, p. 210. Anscombe seems to have envisioned such a treatment of counterexamples. The one that figures in her own text is treated by the remark that it is a mistake to focus on what happens at a moment: “[the agent's knowledge] can seem like an extra feature of events whose description would otherwise be the same, only if we concentrate on small sections of action and slips that can occur in them." (See Anscombe, Intention, \48) For a similar emphasis on the progressive in the discussion of counterexamples see also Falvey, 2000. 
with "more familiar forms of self-knowledge" like selfconsciousness of belief. Reflection on the latter shows, as Thompson puts it in the part of the passage I left out, that the "affirmation of self-knowledge in the sense in question will be [...] the first person of the present tense." After all, the transparency of belief that tends to be taken as the mark of its self-conscious character seems to be restricted in this way. ${ }^{22}$

Once the assumption is in place that practical knowledge is essentially of the present, the restriction of its scope to action in progress follows from the logical grammar of movement predication just rehearsed. Where ' $\phi$ ' stands for a telic action verb like 'to cross the street', the present progressive ' $S$ is $\phi$-ing' and the perfective ' $S \phi$-ed' exclude each other. As long as I am crossing the street, I am not on the other side yet and it is always possible that something interferes before I reach it. But once I am on the other side, I am not engaged in street crossing anymore. There is thus no present perfective. ${ }^{23}$ Consequently, action under the aspect of completion cannot be within the ken of practical knowledge that is in action and thus of the present. Let's call this Presentism about practical knowledge.

\section{Perceiving that iT's done}

Presentism about practical knowledge seems to imply Evidentialism about knowledge of achievements. And if one doesn't want to hold that completion or perfection is known by a special 'sense of achievement' (i.e., a 'how-it-feels-to-

22 Moore's paradox only arises for the beliefs I currently hold. There is nothing paradoxical about 'I believed that $p$, but it is false.' In this respect, my yesterday's beliefs are like the beliefs of another.

23 See Thompson, 2008, p. 125. 
finish'), then the only remaining option is the thesis that Anscombe appears to express in the passage I quoted at the beginning of the last section. The agent knows her work, her completed action, in principle, in the same manner as Oedipus knew those unspeakable deeds he had to call his own: by perception, hearsay and inference.

Even though widespread, the commitment to Presentism isn't always explicit. In the opening paragraph of a recent paper, Barry Stroud appears to suggest a more liberal or inclusive account of the scope of agentive or practical knowledge. His example is of tying shoelaces. He says that he knows how to do it and that when he is doing it, he usually knows that $h e^{*}$ is. Furthermore, he says this: "When I have done it, my laces are tied because I tied them, and I usually know they are tied because I know that I tied them." (Stroud, 2013, p. 1) That sounds promising. It suggests that one "usually" knows the relevant perfective fact about one's intentional action and its intended result in the same manner as one knew the correlated progressive fact in the midst of performing it. At the bottom of the page, however, it is announced that the rest of the paper will "concentrate on an agent's knowing that he or she is doing such-and-such." And what Stroud goes on to say about the latter seems to be in line with Presentism.

In the middle of the paper we are told that knowing what you are doing is a "kind of self-knowledge" that is compatible with not knowing that "you are succeeding in your action in every respect." Stroud illustrates the point by appeal to calculating a sum in one's head: one knows that one is doing so even when one isn't sure whether one will get the correct result. In the case of physical action, the agent's awareness of the "degree of success" is knowledge by perception. On the same page Stroud writes:

"With actions involving bodily movements and tools and other objects, monitoring the degree 
of success of your actions usually takes place through sense perception. You see or hear or otherwise perceive what you are bringing about, even if you do not strictly speaking know by perception that you are intentionally doing such-and-such.” (Stroud, 2013, p. 7)

It would seem that if you don't bring anything about, then the "degree of success of your action" is zero. And if knowledge of what you are bringing about is, quite in general, knowledge by perception, then it follows that knowing that you are succeeding in your action in any respect rests on perception as well. Accordingly, the passage expresses Evidentialism about agentive knowledge of achievement.

Just like Thompson's Anscombe, Stroud takes this to be compatible with the thesis that agent's knowledge of what she is doing is non-observational. I will deny that in $\$ 7$. But let's begin with an initial challenge to Evidentialism about achievements. Consider the following remark that Kieran Setiya makes in passing when he is discussing the relation between desire and belief:

"[The] desire involved in a prospective intention $[\ldots]$ is disposed to vanish when one perceives that one is done. [...] the belief that I am going to cook dinner tomorrow is replaced by a belief about the past when I see that the meal has been cooked." 24

On the face of it, there is a peculiar gap in this short story about dinner preparations. I believe that I am going to make

24 Setiya, 2007. p. 51. Setiya himself doesn't endorse Presentism. But his own view of practical knowledge has a similar consequence. See \$S5-6 below. 
dinner. Later I see a finished meal. Someone must have cooked it, I suppose. But whence the belief that it was me? Because there was no one else around who could have done it? I take it that we are supposed to fill in the blanks. Let's do so while restricting ourselves to the resources available within the framework of Presentism.

According to Presentism it holds that while being in the midst of it I have practical knowledge of my dinner-making in progress. I do it knowingly right until I'm not doing it anymore. But the production process can end in two ways: in completion or by interruption. And given the Presentist's thesis that the scope of practical knowledge is restricted to what can be described in the progressive, the question whether my activity ceased in the one way or the other cannot be settled in the perspective of that manner of knowing. Enter the dinner I see on the table. How could this decide the matter? For all I know, the appearance of a finished meal at the end of the production process may as well be a gift from above or a mere stroke of luck. On the face of it, knowing that I made dinner can't be analyzed into practically knowing my dinner making in progress plus theoretically knowing of a finished meal. The claim to the contrary may be described as a "two factor view" of agentive knowledge of achievements. Its flaw is that it leaves open what the doing known from within has do with the coming about of the thing given to the senses from without. Maybe the difficulty can be resolved through a different conception of the relation between the relevant bits of practical and receptive knowledge. I want to shelve this issue for now. I will return to it in $\$ 8$. Perhaps there are other options.

\section{REMEMBERING THAT IT'S DONE}

In a recent paper on Anscombe, Setiya rejects Presentism about practical knowledge. According to his reading, 
Anscombe is "unfazed" by the transition from first personal action sentences in the present progressive to their perfective correlates: "the expression of practical knowledge survives intact." (Setiya, 2016, p. 165) The evidence Setiya provides for the interpretative thesis strikes me as inconclusive. ${ }^{25}$ But let's bracket the scholarly issue and consider the systematic proposal. It turns on the idea that there are two species of the genus practical knowledge.

Setiya concedes that completion or perfection can't be within the ken of cognition that is characterized by Aquinas' formula. For as Setiya's Anscombe understands the latter, it requires that the knowledge 'causes' its object and that what is known in that manner can't be without being so known. Neither condition, Setiya says, can be met in the case of past achievements. But sometimes "practical knowledge is not the cause of what it understands"; when you know what you have done, "what makes your knowledge practical is not its content or its causality, but its source: it derives from the exercise of knowledge how." (Setiya, 2016, p. 166)

What, then, is an "exercise of knowledge how" such that it can be the "source" of knowledge of achievements? In the final paragraph of the paper we are told that the "basic case" of exercising know how is characterized by Aquinas' formula. This seems to suggest that practical knowledge of what one has done "derives" from practical knowledge that is that cause of what it understands or, more precisely, was at the

25 The passages to which he refers either don't directly concern the question of the scope of practical knowledge or they belong to thought experiments that Anscombe uses to set up a puzzle that threatens the intelligibility of the very idea of practical knowledge. The passage I quoted in $\$ 3$ belongs to her final account that is supposed to dissolve all puzzles. And in that passage Anscombe appears to endorse Evidentialism about agentive knowledge of achievements. Somewhat strangely, Setiya doesn't discuss that passage. 
time. However, it is hard to see how this could be so. With respect to Aquinas' formula, Setiya's Anscombe endorses Presentism. (That was the reason for introducing a second species of practical knowledge.) But given the assumption that the application of Aquinas' formula forces the imperfective in the representation of the content of the knowledge, it would seem to follow that all that the "basic case" can be the "source" of is knowledge that one was doing it and not that one did it. Past action in progress may be in view. But perfection or completion is still beyond the ken.

That way of extending the scope of practical knowledge into the past can be easily accommodated in the framework of Presentism. If I know what I'm doing while doing it, then why shouldn't I still know it later when I'm not doing it anymore? All that is needed for an affirmative answer is the general idea that the function of the faculty of memory is to preserve knowledge. Such retained knowledge wouldn't itself be 'practical' in the sense of being currently productive or the cause of its object. But one might call it 'practical' in an extended sense, insofar as memory preserved knowledge that was productive at the time. After all, we also speak of perceptual knowledge when it is expressed like this: 'I know that there was an elephant in the room, because I saw it with my own eyes.' Of course, memory plays a crucial role. But it just preserves knowledge originally acquired through the exercise of the power of perceptual judgment. The latter may be called the "source" of the knowledge that is retained by memory. ${ }^{26}$

26 It would be madness if the Presentist were to deny the analogous thought about practical knowledge. Thompson's formulation of the doctrine can be misleading in this respect. The apparent restriction of self-knowledge (in the relevant sense) to what can be expressed in "the first person of the present tense" invites the objection that I can be self-consciously aware of already having believed it yesterday. If memory does its work, even the beliefs I don't hold anymore are not just like the beliefs of another. 
The problem is that it cannot be like that in the case of intentional actions under the aspect of completion or perfection. For, the apprehension of one's actual achievements is originally an apprehension of what is in the past. It can never be present. For, there is no act of completion that we can catch in the present. At any moment, the action is either still under way or already complete. That is the difficulty. Once I know that I did it, memory can preserve such knowledge. But as long as we are looking for something that was once self-consciousness or practical knowledge of current action and that can now figure, mediated by memory, as the "source" of knowledge of past action, all that will be available for memory to preserve is knowledge of action in progress. And if all I know is that I was making dinner, then the question is open whether I did make it. Setiya's Anscombe may be "unfazed by the transition from present progressive to perfective past." But in light of the above difficulty it seems that one shouldn't be so cavalier about it. Unless the appeal to the "exercise of knowledge how" as the "source" of knowledge can be interpreted in a different way, the proposed extension of practical knowledge into the past passes Thompson's argument by and thus fails to break the reign of the imperfective.

In fact, that is crucial for a discursive intellect or finite knower. If learning from my mistakes is to be a possibility, then my past judgments that I now exclude as false must stay within the scope of my apperceptive ' $\mathrm{I}$ '. That is true. But it is a distraction. There is no reason for the Presentist to deny any of this. Accommodating it just requires a slight change in the formulation: selfconsciousness of belief is originally of what can be expressed in the present tense. The described self-consciousness of past belief presupposes a scenario in which I was self-consciously aware of it as my current belief. 


\section{Predicting That it WILl BE DONE}

The difficulty doesn't come up in Setiya's paper. Another thesis put forward in the essay may be the reason why. For it already appears to bring achievements into fold. It suggests that the restriction Thompson's argument puts in place is to be lifted not only with respect to completion already achieved, but also with regard to action yet to come: "what we have done so far" and "what we will do in the future" are both supposed to be proper objects of practical knowledge. ${ }^{27}$

Within the framework of Presentism, there can be knowledge in pure or prior intending expressed by a statement of the form 'I'm going to $\phi$. ' But the sentence has to be heard in the register of what the linguists call the prospective imperfective where it is possible to say without contradicting oneself ' $\mathrm{I}$ was going to $\phi$, but never ended up $\phi$-ing. ${ }^{28}$ (Say, I was going to cross the street, but then there was an accident on the road so that I stayed on curb.) So conceived, the object of knowledge in prior intention is not the future occurrence of action, but rather a present tendency that might never manifest itself in action, if something interferes. Setiya's Anscombe, by contrast, insists that knowledge in pure intending is properly expressed in the simple future 'I will $\phi$ ' that has no such "tolerance for failure." 29 And if all failure is indeed ruled out, then the same should hold for interference along the way. Accordingly, it is not just knowing that one will be doing it, but also knowing that one will get it done. That is precisely how Setiya describes it on the preceding page when he specifies what has been excluded in

27 See Setiya, 2016, p. 167.

28 See Thompson, 2008, p. 142.

29 See Setiya, 2016, p. 165. 
the misinterpretations of Anscombe's account: the agent's knowledge that she "will eventually succeed."

Such "practical foreknowledge" is also supposed to be explained in terms of the "exercise of knowledge how." In this case, it is obvious that the phrase can't refer to what was called the "basic case." In the paper on Anscombe it remains, as far as I can see, somewhat unclear what exactly is supposed to take its place. Setiya's own theory of know how provides the relevant alternative. According to his view, it holds that, given certain conditions, the "decision" to $\phi$ can already count as an "exercise of knowledge how to $\phi$ " that is sufficient for knowledge of one's concrete act of $\phi$-ing: Knowledge how to $\phi$ together with knowledge of one's ability to $\phi$ provide the "epistemic warrant" to form the belief that one will $\phi$ in forming the intention to $\phi$. Consequently, such belief is knowledge of the future occurrence of one's action. ${ }^{30}$

The thesis that knowledge in pure or prior intention is already of concrete action introduces a self-standing kind of practical knowledge whose object can't be characterized by Anscombe's knowledge requirement. In his own account, Setiya retracts the latter completely. ${ }^{31}$ In consequence, it looks like action currently in progress can be treated in a parallel fashion. The difference between them is just a matter of the content of the respective mental act or state. The manner of knowing is the same: given knowledge how and knowledge of ability, the intention is by itself sufficient for the truth of what it represents. So conceived, practical cognition is, strictly speaking, never knowledge in action. It is

30 See Setiya, 2008, p., 407. Since Setiya takes the intention to be a belief (a “desire-like belief'), forming the belief and forming the intention are identical.

31 The agent only needs to have a "partial belief" that is she actually doing it. See Setiya, 2008, p. 390. 
knowledge by decision or choice conceived as an item in the mind that is distinct from the action in the world, even when they are present at the same time. David Velleman, who endorses a similar view, puts it like this: one can speak of "practical cognition" where "a question is resolved in the world by being resolved in [the] mind." (Velleman, 2000, p. 25) Let's call this Futurism about practical knowledge, since it implies that insofar as the knowledge is practical one knows one's action currently unfolding in the same way as one might know it before it started.

On the assumption that one can know future achievements in prior intention, the treatment of knowledge of past achievements appears like matter of course. Given that knowledge is practical when it is by decision, knowledge of what one has done will count as 'practical' in an extended sense, when it has an earlier decision as its "source." This seems to sidestep the worry about the transition from the progressive to the perfective. On reflection, however, it just shifts the place of the puzzle.

Aristotle famously denies that we can know the future with respect to worldly affairs such as a sea battle. And one of the reasons he gives is that this would leave no place for deliberating about what to do. ${ }^{32}$ The perspective of deliberation and choice implies an asymmetry between the past and the future. The past is determined, the future is open. That is why deliberation and calculation are concerned with the latter and not the former: "Nothing that happened in the past is subject to decision" For no one can change it. Deliberation and calculation are of "what can be otherwise." 33 One might think that this is compatible with the idea that one can determine the future by choice. But that would be tantamount to the thought that nothing can

32 See Aristotle, De Interpretatione, $18 \mathrm{~b} 31$.

33 See Aristotle, Nicomachean Etbics, $1139 \mathrm{~b} 6$ and 1139a14.

Manuscrito - Rev. Int. Fil. Campinas, v. 41, n. 4, pp. 195-253, Oct-Dec. 2018. 
interfere with its execution. Human action is not like that. My action's being uninterruptable would require my total control over all external conditions. And in order to have such control I would have to make the world rather than act in it. The perspective of acting also implies the openness of the future - no less than the perspective of deliberation, even though for different reasons.

Velleman appears to avoid this difficulty by insisting that the "ordinary standards" for knowledge are the following: provided that it gets done in the end, the agent can be said to have known her future performance, even though the "residual possibility of error" was not ruled out at the time. ${ }^{34}$ However, in some passage it sounds like his variety of Futurism about practical knowledge is, in fact, compatible with Evidentialism about agentive knowledge of one's actual performance. Velleman suggests that the doctrine that one can know one's future action by decision removes any difficulty attached to the idea that one knows one's present intentional action by observation:

“[...] you cannot immediately see what you're doing simply by watching yourself do it. But if you already know what you're going to do, then you will be able to see that you've started doing it, so long as you're watching at the time." 35

It is hard to see why this should be so. Imagine that I have the prospective intention to wiggle my right toe once tomorrow morning. When the sun rises the next day there

34 See Velleman, 1989, p. 56.

35 Velleman, 1989, p. 51. Later in the book it turns out that Velleman takes this to be the "normal" case. Usually one finds oneself moving; it is just that one knew that one would be. See Velleman, 1989, p. 142. See also Velleman, 2015, pp. 339-340. 
are two toe-wigglings occurring shortly after each other. How do I know which one of them, if any at all, is my intentional action? If there ever was a difficulty about knowing what one is doing by watching oneself do it, Velleman's "self-fulling expectation" won't make a difference - unless it can provide the link to the particular goings-on when they come to be.

Even though he thinks there is no need for it, Velleman notes what would provide the missing link such that there is no need for an additional act of perception: The intention would have to include an exact specification of time within its content. Once the time of action comes, it would have to turn into the "intention to do it now." 36 That is how Setiya presents the transition to knowledge or belief of present action when he gives the rough version of his view: "[...] when I intend to $\phi$ right now, I believe that I am going to $\phi$ right now, and so believe that I am $\phi$-ing." 37 However, since the progressive and the perfective have different truth conditions, a further step is required. There also has to be a transition from the belief that one will get it done at $t$ to the belief that one got it done or is done now. But that replacement of ' $\mathrm{t}$ ' cannot happen within the content of the intention. As Setiya himself noted in his short story about dinner preparations, intention gives out with completion. One can't intend to do what one has done already. (Unless one decides to do it again.) But if one can't intend in the face of completion, then one can't know it in intention.

Including reference to the time of action in the content of the intention won't do the trick. It cannot provide the missing link. In consequence, we seem to be back at Setiya's original version of his short story about dinner

36 Velleman, 1989, p. 141.

37 Setiya, 2012, FN 32, p. 304. 
preparation. The agent must somehow find herself having done it. But how? What kind of perceptual finding could play that role? That was the question I shelved at the end of $₫ 4$. Before I finally turn to it, let me add a final piece to the puzzle.

\section{IN THE BEGINNING WAS THE DEED}

Presentism and Futurism both rest on the assumption that practical knowledge of what one is doing doesn't require knowing what one has done so far with respect to the task at hand. In the case of Presentism this is obvious. It directly follows from the doctrine that only the imperfective can appear in the content of this form of cognition. In the case of Futurism, it is am implication of the claimed parallel between practical knowledge of present action and practical knowledge of future action. The status of the respective belief as knowledge is supposed to be explained through the idea that, given certain conditions, the intention is by itself sufficient for the truth of what it represents. In Setiya's version of the view, it is knowledge how and knowledge of ability that provide the epistemic warrant to form the "desire-like belief" that one is hereby going to do it or that one is hereby doing it. But however those conditions are specified, the crucial point for the present purpose is that since past action is not a possible object of an intention, knowledge of what one have done so far cannot be contained within the posited desire-like belief that one hereby be doing it now. The same holds for knowledge of what one was doing. It follows that practical knowledge of what I am doing leaves open what was up with me a moment ago.

The Presentist wouldn't accept the second implication. But considering why it is untenable will help to see that the first one is just as problematic. That Setiya is committed to both comes out in his doctrine about starting. Intuitively, ' $S$ 
is $\phi$-ing' entails ' $S$ started to $\phi$. ' Setiya would agree. But he denies that the entailment carries over to the intensional context of the description under which the action is intentional. According to his view, ' $S$ is intentionally $\phi$-ing' does not entail ' $S$ intentionally started to $\phi$.' The beginning of the movement could be unintentional. For doing it is one thing, beginning to do it another. If the action is to be intentional right from the start, then there must be two intentions: the intention to be doing it and the intention to begin doing it. What leads to this doctrine is the thought that the intention that "sustains" or "guides" the "action as it goes on" cannot explain or be the cause of "one's beginning to act", since the content of the "intention in acting" is the proposition that one is $\phi$-ing. ${ }^{38}$ When that proposition is true, the starting has already happened. But the past can't be the object of an intention. So beginning intentionally must be a separate act that requires a distinct intention. ${ }^{39}$

With this the Presentist can't agree. The idea of an act of starting gives rise to the same puzzle as the idea of an act of completion: We can never catch the posited act in the present. The assumption that those verbs describe separate acts in addition to the performance under way is incompatible with Aristotle's point that as movement or change in material reality action is essentially extended in

38 See Setiya, 2007, p. 57.

39 In his version of Futurism, Velleman avoids this multiplication of the intentions by insisting that the initiation of the action at a particular time is never by practical reason. It is thus not known practically, but rather by perception: You find yourself having started doing something. The role of practical reason is to supervise actions that got started. The beginning of the actual motion is "initiated" by the "body." (See Velleman, 2015, 340). 
time and for this reason infinitely divisible into phases..$^{40}$ As Anscombe puts it, there is "no first moment of moving, but only a last moment of rest, at any moment after which the moving body already has been moving." (Anscombe, 1981, p. 192) One can't apprehend movement or change as long as one focuses on what is the case at an instant. Accordingly, ' $S$ is $\phi$-ing' entails ' $S$ was $\phi$-ing a moment ago.'

Since subtleties about the limit lead to technical puzzles all over the place in philosophy, perhaps one shouldn't worry too much about what an action theorist says about starting and stopping. But the rot immediately spreads to the center and infects the heart of agency: that time in the midst of doing where the action is present, alive and supposedly for its subject. The thought that made it look like the inference from ' $S$ is $\phi$-ing' to ' $S$ started to $\phi$ ' can't be valid in the intensional context of the descriptions under which the action is intentional will also make the continuity of movement that is invoked by talk of "guiding" and "sustaining" disappear from the perspective of practical knowledge.

In one passage Setiya comes close to stating this consequence. Consciousness of one's unfolding action, he says, involves a "dynamic epistemology": "As knowledge of the present, [it] must be renewed as time goes by. In effect, I have to form the belief that I am clenching my fist now at each new moment." (Setiya, 2008, p. 407) The talk about "renewing" one and the same bit of knowledge obscures the fact that the theory should predict a series of distinct desirelike beliefs. Remember that the epistemic warrant to form a belief of that special kind is supposed to be provided by knowledge how and knowledge of ability. Given those two conditions, that act or state of mind is supposed to be by

40 See Aristotle, Physics, 231b18-232a22. See also Thompson, 2008, pp. 111-112. 
itself sufficient for the truth of what it represents. By the same token, it cannot represent what was happening before. In this respect, the fist clenching that was going on a moment ago stands in the same way to the posited desire-like belief that I am clenching my fist now as the intention in acting stands to beginning to act. In the latter case the conclusion was that there has to be a further intention if the movement is to be intentional right from the start. The same reasoning suggests that, strictly speaking, each moment of fist clenching is the object of a different desire-like belief. In the resulting picture it becomes mysterious how the continuity of progression ever enters the perspective of practical knowledge. From that point of view, there only appears to be a mere concatenation of states that each hold for a moment. What unites them into one continuous movement seems to be beyond or below the ken of practical knowledge.

The source of the problem is the Futurist's thesis that practical cognition is knowledge by decision. The Presentist avoids the difficulty by insisting that knowledge in pure or prior intending is just knowledge of a tendency to move. Practical knowledge of actual movement is reserved for the intention in action. The problem is that excluding completion from its ken renders it unintelligible how the difference between a mere tendency to $\phi$ and actual $\phi$-ing can be known in the perspective of practical cognition. For, the issue about knowledge of completion isn't restricted to the end. It arises with the very first step. The strategy to concentrate on the agent's knowledge of what she* is doing while leaving the treatment of her knowledge of what she* has done for later is not viable, since the latter is already contained in the former.

Just as Anscombe does in the passage I quoted at the beginning of $\$ 3$, Stroud acknowledges that "you usually need to be aware that one step in the process has been completed successfully in order to go on correctly to the next." (Stroud, 2013 , p.7) The formulation leaves space for the possibility of 
going on to the next step without knowing that the previous one has been properly executed. No doubt, that can happen on occasion. In another respect, however, the connection between knowing what one is doing and knowing what one has done is much tighter than the formulation suggests. Actual movement differs from a mere tendency to move in that it contains a phase that is already complete. So unless the agent knows of at least some step that she has completed successfully, she doesn't know that she* is actually doing it.

Consider watching a tree fall over. The experience of this motion in progress always involves the apprehension of the bits of space the tree has already traversed in its fall. When you haven't experienced any bit of falling through a segment of space, then you are not watching it fall. Perhaps you saw that it got uprooted. Consequently, you may be said to know that it is going to fall eventually. But if it hasn't moved yet, then it is not falling. So all you know is its present tendency to fall. A tendency that might be prevented from manifesting itself in actual motion. Perhaps the next moment something gets jammed into the tree so that it doesn't end up falling.

This feature of the experience of motion reflects a crucial aspect of the logical grammar of movement predication. Where ' $\phi$ ' stands for a telic verb, the progressive ' $S$ is $\phi$-ing' differs from the prospective imperfective ' $S$ is going to $\phi$ ' in that for the former the following conditional holds: $S$ is $\phi$ ing only if $S \phi^{*}$-ed - where ' $\phi^{*}$ ' signifies a part or phase of $\phi$ ing. By contrast to the prospective imperfective, the progressive doesn't just reach ahead to what may or may not come; it also collects the past, the completed phases of the on-going movement it describes. This follows from Aristotle's point, once one considers directed movement. Insofar as the movement is progressing towards a terminus, any progression that has been going on after the last moment 
when the body was at rest is now a perfected bit of progress. ${ }^{41}$

As it derives from a general point about the reality of directed movement or change, this feature of the telic progressive determines a requirement for knowledge of directed movement. ${ }^{42}$ According to Presentism, perfective facts cannot be within the ken of practical knowledge. Given Aristotle's point, it follows that the difference between the prospective imperfective and the progressive is untraceable in the perspective of such cognition. And if that distinction is untraceable, then one's actual progress in doing something cannot be known in that manner. All that remains to be known is one's tendency to do it. But one already knows that when one knows what one intends or wills to do. Given the restrictions that Presentism puts on the object of practical cognition, the talk of knowing what one is doing threatens to

41 Aristotle himself presents this as a consequence of the continuity of movement. See Aristotle, Physics, 237a9-12.

42 One might deny this consequence. That $p$ entails $q$ doesn't mean that one can't know that $p$ unless one knows that $q$. So why should it be different here? The objection neglects that our inference pattern defines the very idea of directed movement or change. Consider the following scenario. Say, the only difference between two kinds of objects $a$ and $b$ resides in the fact that the former contains $c$. Accordingly, you won't know whether the thing in front of you is $a$ or $b$, unless you know $c$. And if your current perspective on the thing is to be sufficient to settle the question, then $c$ must be available from this point of view. It is the same with our distinction between actual moving and a mere tendency to move. Since the difference between them resides in the fact that the former contains a completed bit of movement, knowing the truth of the progressive requires knowing of some perfective fact concerning a subordinated part or phase of the overarching process. And if actual progress is to be within the scope of a certain way of knowing, then such perfective facts have to be available within the perspective of that manner of knowing. 
boil down to a funny way of saying that one knows what intends to do. Accordingly, Presentism about practical knowledge would be tantamount to what one might call Volitionalism about practical knowledge. That is, the doctrine that, strictly speaking, the object of practical cognition is just the determination of one's will. On the face of it, Volitionalism about practical knowledge entails not just Evidentialism about achievements, but general Evidentialism about knowledge of action unfolding in the material world.

Anscombe herself regards the latter view as untenable. She calls it a "mad account": "[...] to say that what one knows as intentional action is only the intention, [...] and that the rest is known by observation to be the result which was also willed in the intention [...] is a mad account." (Anscombe, 2000, \$29) The argument behind the harsh verdict is not easy to make out. As I understand it, it derives from her criticism of the metaphysical version of Volitionalism that restricts the domain of agency to acts of willing. That she calls "non-sense" in the next paragraph. One can't understand oneself as willing or intending something, as long as one takes it to be a mere accident or "grace of fate" if the relevant thing ever happens in the outside world. For the idea of its efficacy is precisely what distinguishes willing from mere wishing. This problem of metaphysical Volitionalism is, as it were, inherited by epistemological Volitionalism that restricts what one can know in the perspective of agency to the determinations of one's will. For nothing given in perception can show me that what I see happening springs in the right way from my volition. And if I can't know the efficacy of my will, then the whole notion of reason being practical would have to appear to me as mere a fixed idea I somehow find myself with, but that has no rational ground. The introduction of the notion of practical knowledge is supposed to show us the way out 
of "madness" and "non-sense." But the Presentist rendering of its object seems to lead right back into this mess. ${ }^{43}$

\section{TWO FALSE AVENUES OF ESCAPE}

If Anscombe's rejection of epistemological Volitionalism is sound, then the considerations of the last section should amount to a reductio of Presentism. But one might think that the absurd consequence can be avoided in something like a broadly Presentist framework. Two junctures in the argument seem to leave space for a route of escape. One might try to modify Presentism in order to block the inference to epistemological Volitionalism. Alternatively, one might attempt to revise the latter in order to block the inference to general Evidentialism about agentive knowledge.

Let's begin with the former strategy. Why shouldn't the Presentist take the above considerations as a friendly

43 It may seem different, since the idea of a tendency already contains the idea of efficacy. The upshot of Anscombe's considerations is that knowledge of one's intention is misconceived if one takes it to be knowledge of an inner state or act. Developing what he takes to be one of her central insights Thompson describes "intending" as a form of the imperfective. (See Thompson, 2008.) Similarly, John McDowell suggests that an intention should be conceived as an "action in waiting." (See McDowell, 2011, p. 16.) Some will want to add that even intending for the future already involves present acting. After all, it involves preventing oneself from doing what one knows would make it impossible to execute one's intention later. This may all be true. But it wouldn't help if it was presented as a response to the current difficulty. One can't understand intentional action by only considering omissions. Similarly, we couldn't have practical knowledge of our tendencies to move, if we couldn't ever practically know their manifestations in actual movement. 
amendment? Perhaps the view can be corrected in order to accommodate the inference pattern marking the difference between a mere tendency to $\phi$ and actual $\phi$-ing in progress. One might try saying that when I know what I am doing, I inevitably have knowledge of something I have done already: I started doing it. But that won't do as a response. It follows from Aristotle's point that starting to do something is not a self-standing act. The truth of ' $S$ started to $\phi$ ' comes down to the fact that $S$ has done something in the way of $\phi$-ing that can be described by ordinary action concepts. When it occurs in our conditional ' $S$ is $\phi$-ing only if $S \phi^{*}$-ed', the variable ' $\phi *$ ' has to be read as standing for a telic verb that admits of the aspectual contrast. So conceived, the conditional states that the truth of the progressive requires a perfected bit of progress.

There is a less sophistical version of the maneuver. It would only require a minor adjustment of the original formulation to conceive of Presentism in such way that it can accommodate a version of our conditional in which the agent's knowledge of completed phases occurs within the scope of an existential quantifier. Say, something along the following lines: $S$ knows that $s h e^{*}$ is actually $\phi$-ing only if $S$ knows that there is some $\phi^{*}$ such that $s h e^{*}$ has $\phi^{*}$-ed. This is still compatible with the thesis that for any specific or concrete ' $\phi^{*}$ ' the agent's knowledge of completion is not practical. But this won't do either. The agent's knowledge of the reality of her action unfolding in space and time would be merely abstract. And it can't be like that all the way down and for all descriptions under which her action is intentional. On some level, the agent's knowledge of completion along the way has to be concrete. It is not enough for her to know that there is some phase or other that is complete; she has to know of a specific one. Accordingly, the proper way to state our requirement is this: $S$ knows that $s h e^{*}$ is actually $\phi$-ing only if for some specific $\phi^{*} S$ knows that $s h e^{*}$ has $\phi^{*}$-ed. 
Of course, it is possible to know that $S$ is $\phi$-ing without knowing of any specific phase that is complete. Say, you acquire knowledge by hearsay that the palace is in process of collapsing. That doesn't mean that you know how much of it has collapsed already. Some part must have. That you know. But not which one. Similarly, I might infer from the cheering noise that the race has started. Such knowledge of a race in progress doesn't contain specific knowledge of how far along the track the runners are. But note that in these examples the knowledge of movement or change is, so to speak, 'mediated': through telling in the one case, through inference in the other. Both are derivative - dependent on the other's direct experience of the building's collapsing or on one's own perception of the cheering noise.

It is different when the knowledge of movement or change is 'immediate' or 'direct'. When watching a building collapse or a tree fall over, the experience of the fall in progress requires memory to hold the apprehension of the bits of space traversed already within one's present imagination. The respective idea of completed phases can't be abstract, because the perceptual judgment of movement or change is, as Kant would put it, a temporal synthesis of what was, what is and what is going to be. Unless an apprehension of a concrete completed phase is brought into the unity of the experiential judgment of movement currently unfolding, the only thing that could come into view for the subject would be a state that holds at a moment. If it is not to be 'mediated' by hearsay or inference, then it must be the same with the agent's knowledge of her intentional action in progress. But the temporal synthesis has to be somehow within her practical consciousness.

On occasion, one may know very little about what one has achieved so far. Perhaps you are not even sure whether you are headed in the right direction. Still, unless you are 'directly' aware of specific moves you have made, you are not directly aware of being on your way. Within the perspective 
of such unmediated or non-inferential knowledge, the actuality of your action in progress would be nothing to you; the only thing that would remain to be known in that fashion would be your willing or intending.

Blocking the inference to epistemological Volitionalism requires rejecting Presentism and not just amending it. This leaves the second juncture of the argument. Maybe epistemological Volitionalism can be amended in a way that blocks the inference to generalized Evidentialism about agentive knowledge of physical action. One might try replacing the doctrine that the object of practical cognition is just the determination of one's will by a more qualified thesis. Perhaps something along the following lines: Practical knowledge, just on its own, can't adjudicate how far the respective act it causes and understands extends beyond the inner limits of one's body and into the material world. All by itself, that is, practical cognition won't be knowledge of the degree of success. It is just knowledge of one's tendency. That seems to capture epistemological Volitionalism insofar as it is implied by Presentism. But why shouldn't this be compatible with the following thesis: aided by the contributions of the receptive facutly, practical cognition can amount to knowledge of actual movement or change in the material world?

If I understand him correctly, John McDowell suggests a version of this view in a paper on Anscombe. ${ }^{44}$ In any case, something along these lines must be what Stroud has in mind when he says that "monitoring the degree of success of your actions usually takes place through sense perception", even though "you do not strictly speaking know by perception that you are intentionally doing such-and-such." 45 It seems

44 See McDowell, 2013.

45 Stroud 2013, p. 7. On the face of it, the view is incompatible with Anscombe's knowledge requirement. For, why should my 
apt to ask how the receptive faculty is supposed to provide the envisioned help or aid. That is another way of asking the question I shelved at the end of $₫ 4$ : What is the proper way to conceive of the relation between what the agent knows from within and what she knows from without, by the use of her senses, such that the combination can amount to her knowledge of her work?

Of course, once one knows, under some description, of one's agency being at work in the material world outside the limits of one's body, one can learn by perception, hearsay and inference about other things that one is doing or has done by doing or having done those things knowingly. That was the form of Oedipus' epistemic endeavor. And for the purposes of the present argument I am happy to grant that it may be like that with respect to some or even many of our achievements. ${ }^{46}$ The question is whether it can be like that all the way down, for all my achievements in transacting with objects in the world.

Now that we have seen that it doesn't just concern the final product, but arises with the very first step and thus includes the query whether one is actually doing anything at all, the difficulty comes out more clearly: I knowingly will it to happen. Then I see it happening. But what is the connection? That was Hume's problem. That epistemological Volitionalism gives rise to it is the reason why Anscombe brands it as a "mad account." The view under consideration seems different, because of its thesis

action cease to be intentional under a description just because I forget to monitor the respective degree of success?

46 Often one has to check whether it really worked. This may involve asking other people. Sometimes it even requires complicated investigations to ascertain whether the apparent result of one's action is indeed one's work and not just something that came about as an accidental side-effect or perhaps entirely independently. 
that in virtue of the aid by receptive knowledge the agent knows directly, rather than by inference, that the action of which she is agentively or practically aware is an actual happening in the outside world. But the difficulty remains the same: If my knowledge from within doesn't by itself reach all the way to the material I am working on, then how could my knowledge from without show me that what is happening with it is what I am intentionally doing to it?

For my use of the senses to show me that, my perception or experience of the happening would have to have some special character or quality through which it is presented to me as my intentional action. One might conclude that this is precisely what we need: the idea of a special kind of practical perception of one's own action. ${ }^{47}$ For that to do any work in the context of our problem, it would have to be an experience of the 'because' that links the volition and the motion in the right way. But if we could take care of the difficulty simply by availing ourselves of a special sense that presents my physical motions to me as intentional, then we might as well stick to the more familiar version of this thought that Anscombe ridicules as the idea of "a very queer and special sort of seeing eye in the middle of action" and that has recently made a revival under the title of the "sense of agency." 48 For the present purposes, it suffices to say that in such a framework there wouldn't be a need for the notion of practical knowledge in the first place.

47 See Schwenkler 2015, pp. 27-28.

48 See Anscombe, 2000, \$32. 


\section{KNOWING BY DOING}

With the two avenues of escape having turned out to be dead ends, I can return to the conclusion of my argument and the question of its significance. It seems to me that it establishes that Presentism and Futurism are equally untenable. If there is to be such a thing as practical knowledge of what one is doing, then knowledge of what one has done so far must be contained within it. One might conclude that this shows the unintelligibility of the very idea of practical knowledge. Perhaps there is an alternative.

Let's revisit the received action theoretic casuistry and the lessons commonly drawn from it.-The significance of counterexamples like the celebrated carbon copy case Davidson designed has to do with the specific way in which Anscombe approaches the topic of practical knowledge namely: through her knowledge requirement. It is a different matter what follows from the battle over counterexamples for the question of the possible scope of knowledge that is "the cause of what it understands." Why should what must be known in that manner by a subject if she is to count as $\phi$-ing intentionally determine what can be in the scope of such cognition, if all goes well? In this connection it seems worth noting that in ordinary parlance it depends on the context whether or not ' $S \phi$-ed intentionally' entails ' $S$ knew of her success at the time.' Even if one replaces the variable ' $\phi$ ' with 'killing.' Claiming ignorance of success at the time of leaving the scene of the crime will certainly be a meager defense against a murder charge. But in your negotiations with a contract killer, the job is likely to only count as done, once she is in the position to say 'He is done.'

As long as one sticks to killing, the second usage of the perfective will seem like a gratuitous bit of surface grammar that doesn't need to be included in the philosopher's collection of the logical forms of action sentences. Things begin to appear in a different light when one turns to the 
activity that according to Marx and Engels is distinctive of our form of living: We produce our food. ${ }^{49}$ It sounds rather odd to say that the task of preparing a meal was fully executed when the agent left the scene without knowing whether there was a meal as the result of those labors. That is not what I would expect if you told me that our neighbor made dinner for us. Of course, it is easy to come up with cases where the agent doesn't know of his success and we would nevertheless hold true the respective proposition about his achievements in the preparing of dinner. Still, it is hard to ignore the manifest oddity of serving dinner with the sincere comment 'I have no idea whether this is at all edible.' Intuitively, the proper completion of the task of making food goes together with knowing that the result or product of one's act of production is indeed edible.

The mere fact that we can find such entailments in ordinary language is, of course, not decisive or, as such, philosophically significant. Any "two factor view" of agentive knowledge of achievements could easily accommodate such data. Perhaps there is a convention to only count it as a proper case of 'making dinner', when the agent saw that it was good and concluded that he made it. However, further reflection suggests another interpretation of the fact that action sentences about acts of production like building a house or making dinner can occur in a register where the inference from 'intentionally' to 'knowingly' is valid even under perfective aspect. Namely, an interpretation that reverses the terms of Setiya's short story about dinner preparations. The latter goes like this: Upon seeing a prepared meal, the subject forms the belief or acquires the knowledge that $s h e^{*}$ is done with making dinner. Could there be a case where the opposite is closer to the truth? That is to say, a case where the following holds: In virtue of completing

49 See Marx and Engels, 1978, p. 21. 
the cooking process, the cook knows of the thing she looks at that it is food, something that is fit to eat.

Once again, the choice of examples tends to set the tune in which the action sentence schemata are heard. The role of cooking in epistemically determining or ensuring that the stuff is edible is easy to forget when the only culinary thing that happens in the philosopher's kitchen is, say, the pouring of coffee or the buttering of toast where all the ingredients came in packages with expiration dates printed on them. But that is clearly not the basic case. Originally, one of the crucial functions of cooking was to make stuff edible that otherwise wouldn't be. And we can easily arrange for our environment to become so hostile that all preparation of food requires the level of expertise that an apprentice in the art of preparing Fugu Sashimi has to exhibit in order to acquire a license in Japan. Under such conditions it would be obvious that cooking done properly is a process that culminates in knowing that one's product is fit to eat. Dialogues along the following lines would be quite common. Smith says to Jones: 'This is edible.' Jones asks: 'How do you know?' And Smith responds: 'I cooked it.'

In this little exchange, an action sentence figures in the same position as observation reports do in the standard sample dialogues in a textbook on epistemology. It is offered as an explanation of how one knows that a given object has a certain property. Just as the subject of the standard textbook sample declares, 'I know, because I saw that it is so', Smith may be found saying: 'I know, because I made it so.' If this way of speaking can be taken at face value, then it follows that just as there is knowledge by perception, there is such a thing as knowing by doing. ${ }^{50}$ In ordinary parlance, this manner of speaking is quite common. If you were to ask me how I know that my spatula is in the left drawer of my

50 For an extended discussion of these points see Haase, forthcoming. . 
kitchen cabinet, I would respond that I know, because I put it there. It is in connection with this way of explaining how one knows something that perfective action sentences appear in the register where ' $S \phi$-ed intentionally' does entail ' $S$ knows that $s h e^{*} \phi$-ed.' For, if Smith were to ask you how I know that my spatula is in the left drawer of my kitchen cabinet, you are now in the position to respond: 'He made sure of it. He put it there himself.' This suggests an interpretation of the entailment according to which it holds where the action that had the intended result $p$ was performed in such a manner that it was not only sufficient for the truth of $p$, but also for the subject's apprehension of her act's sufficiency for the truth of $p$. Where this is so, the agent came to know that $\mathrm{p}$ through acting or by doing.

The case of preparing a dish of Fugu Sashimi provides a vivid illustration of why it seems prima facie plausible to think that this manner of speaking may not be analyzable in terms of a "two factor theory" of agentive knowledge of achievements, but expresses a distinctive way of knowing or coming to know. For the crucial property of the product that decides over the difference between 'success' and 'fatal flaw' - namely, that it is fit to eat and thus food, rather than a lethal dosage of poison - is in this case not something that one can come to know just by staring at the slices of pufferfish on the plate. This feature of the thing the cook sees couldn't figure in Setiya's short story about dinner preparations. For it all depends on whether the dish was properly prepared. Not that there isn't a quite immediate way to find out. But who is to step forward as a test subject? In any case, it would seem that, provided all went well and nothing interfered, the expert with the knife knows it in a different way. And if she does, then her knowledge that this thing is edible will be inseparable from her knowledge why it is edible that points to her own agency as the relevant cause. Both bits of knowledge about the dish in front of her eyes will be derived from her 
exercise of knowledge how to use a knife on a pufferfish that resulted in that dish. ${ }^{51}$

Of course, it possible that Smith only thinks that she knows. Perhaps she made a grave error along the way and in consequence is about to tragically kill Jones with what was meant to be a generous offering of food. But this doesn't show that she couldn't ever know in that manner. The possibility of failure doesn't undermine the idea that, if all goes well, the producer comes to know the relevant properties of her product through the act of production.

The notion of knowing by doing obviously stands and falls with the idea that there are two ways of knowing what one has done. The answer 'I made it so' couldn't settle the question 'How do you know that $p$ ?', if it just gave rise to the query how one knows that one did it. One might conclude that one first has to explain how there can be agentive or practical knowledge of achievements before one can turn to the more specific and more complex idea of knowing the properties of an object by making it. But this may be the wrong way of entering the equation. Perhaps the latter supplies the central clue to the former. The young Marx suggests that that manner of knowing objects in the world is constitutive of knowing oneself as a rational agent, a Gattungswesen in his terminology. Accordingly, knowing objects by changing them so that "[one] sees [oneself] in a world that [one] has created" is necessary to know one's own agency. .52

51 This is not to deny that such a thing can't be done without perception. But that perception is part of the action and it is informed by respective know how. In the traditional way of doing it, filleting a fish essentially involves looking at the fish right from the start. And how to spot tiny fishbones is something one learns when acquiring this skill.

52 See Marx, 2009, p. 91.

Manuscrito - Rev. Int. Fil. Campinas, v. 41, n. 4, pp. 195-253, Oct-Dec. 2018. 
If this is correct, then knowing the properties of an object by making it provides a central clue for the question in what sense an agent can be said to have practical knowledge of her achievements along the way and thus of the actuality of her action in progress: not in intention, but through its execution - by doing. To properly develop an account along these lines more would have to be said. Here I just want to suggest that this is what is needed to make sense of the idea of practical knowledge.

\section{AgENCY AND ALIENATION}

The passage from Marx I just quoted famously leads into his description of the contemporary conditions which make it, according to Marx, impossible for the agent to see herself in the product of her work. In effect, she is "alienated" from what she has done and consequently from her being as Gattungswesen. Nevertheless Marx holds that the concept of intentional action wouldn't exist, if it weren't for that manner of knowing. This is often thought to be paradoxical. It helps somewhat to point out that Marx is concerned with that higher stratum of practical knowledge that Aristotle calls phronesis and Hegel christens "objective spirit": knowingly living well together. On a more pedestrian or technical level, Marx's worker knows the product as her work - and not by evidence, but through her exercise of the kind of expertise required for the job. But that only helps to a degree. It seems to just shift the place of the puzzle. If it is only a problem that concerns some higher kind of practical knowledge, why should it undermine the worker's self-understanding as a rational agent?

In certain respects, the puzzle about Marx's alienated worker is akin to the one we started with. If one takes Oedipus' calamity to show that the scope of agentive control is restricted to the determination of the content of one's will, 
then it seems clear why he is so depressed: He never really had agency in the first place. But that renders it mysterious why he would beat himself up about what happened. If, on the other hand, one insists that on some level he had proper practical knowledge of his action, it becomes hard to see why the discovery about those other aspects of what he did should be so paralyzing. One is bound to oscillate between these alternatives, as long as one approaches the notion of practical knowledge through the analogy between the 'I think' and the 'I do'. The analogy suggests that Anscombian practical knowledge is an extension of the familiar sphere of self-consciousness into the material world. That is how Thompson initially presented the "overarching thesis of Intention": "self-knowledge in this familiar sense extends beyond the inner recesses of the mind, beyond the narrowly psychical, and into the things that I am doing." (Thompson, $2011,200)$ In one way of hearing it this suggests that the character of our spontaneous control or knowledge is the same whether we are talking about our beliefs and choices or about our intentional actions. But it obviously can't be like that with respect to all aspects of one's movement in the world - even if one focuses only on descriptions under which it is intentional. Accordingly, it seems inevitable to restrict the scope of practical cognition to a certain understanding of the progressive where its contrast to the prospective imperfective isn't fully in view.

Thompson's formulation, in fact, leaves open whether the character of spontaneous control or knowledge remains the same throughout the proposed extension of the sphere of self-knowledge into the material world. In another approach this question is decided in the affirmative. Eric Marcus recently called this approach Normativism about practical knowledge. It rests on the assumption that intentional action can be identified with a normative judgment about what is to be done. Given the equation, knowing what one is doing can be explained in the same fashion as the more familiar 
knowing what one believes. Marcus writes: "If actions are judgments, then whatever explains an agent's knowledge of the relevant judgment can explain her knowledge of the action." 53 As I understand it, the proposal is this: To judge ' $p$ is to be believed' is to believe that $p$. Accordingly, selfconsciously taking $r$ as a conclusive reason for believing $p$ is to know that one believes that $p$. So too with intentional action: To judge ' $\phi$ is to be done' is to determine oneself to $\phi$ and thus to perform an act of $\phi$-ing. Accordingly, selfconsciously taking $r$ as an all-out reason to $\phi$ is to know that one is $\phi$-ing.

One would expect Normativism to be a form of Presentism. After all, the analogy between knowing what one is doing and knowing what one believes is the central juncture of the argument for Presentism that Thompson presents on Anscombe's behalf. Marcus, however, insists that Normativism does not entail Presentism. He accepts the requirement that a proper account of practical knowledge has to explain how achievements can be within its ken and then goes on to argue that his view can meet this condition of adequacy. He offers several options. The one that seems most promising exploits the following feature of the relation between the imperfective and the perfective: If nothing interferes, progress is sufficient for completion.

The point follows from Ryle's remark about achievements that I quoted in \$3. Since progression doesn't entail completion, one can say that doing something is one thing, completing or finishing it another. But that doesn't mean that 'finishing' signifies an additional act that one has to perform at the end of the interval during which it is true that one is $\phi$-ing. That would be absurd. It would follow we couldn't get anything done by doing something. The only

53 Marcus, 2018, p. 1. See also Moran 2001, p. 127; Rödl, 2007, Chap. 3 and Marcus 2012, Chap. 2. 
thing that Smith has to do in order to arrive at the other side of the street is to keep crossing it. Now, Marcus suggests that the same is true of practical knowledge: "Just as completion itself does not require more than progress, knowledge of completion does not require more than knowledge of progress." (Marcus 2018, 22) Not just any knowledge of progress will do, of course. Otherwise 'I was $\phi$-ing' would entail 'I $\phi$-ed.' Rather, I have to keep doing it knowingly until I thereby come know that I have done enough. If the thought I gestured towards in the last section is true, then something along these lines must be right: In the fundamental case, skilled or knowledgeable doing generates knowledge of what one has done.

What I don't see is how this thought is supposed to be available within the conceptual framework of Normativism. As Marcus presents it, the response to the challenge goes basically like this. Since Normativism has given an account of practical knowledge of what one is doing, the appeal to the fact that progress can be sufficient for completion makes it possible to extend that account to knowledge of what one has done. But this presupposes that Normativism has indeed provided an adequate account of knowledge of what one is doing. And that is precisely what one might doubt on the ground that knowledge of what one has done so far must already be contained in knowledge of what one is doing.

The crucial question is whether the respective knowledge of achievement along the way fits into the register through which Normativism proposes to understand practical cognition - namely: the thesis that since $\phi$-ing intentionally is identical with the normative judgment that $\phi$ is to be done, it holds that "whatever explains an agent's knowledge of the relevant judgment can explain her knowledge of the action." When Marcus characterizes the way in which such cognition is related to its object he endorses Anscombe's conditional ' $S$ is $\phi$-ing only if $S$ knows that she* is $\phi$-ing.' In Marcus' 
words: "without the knowledge [that one is doing it], one would not be performing the relevant action." (Marcus 2018, 4) And that seems to be suggested by the claimed identity between the action and the judgment. At least, as long as one takes it that the latter can't be framed without being aware of framing it.

That conception of the relation between self-knowledge and its object seems to be also at work when Marcus presents the transition to knowledge of achievement: "Once I have done enough to finish $\mathrm{x}$-ing (and thus to know that I have finished $x$-ing), I will have practical knowledge not only of my having been x-ing, but of my having x-ed." (Marcus 2018, 22) The "thus" that figures in the brackets seems to suggest that since intentional actions are essentially performed knowingly, reaching completion inevitably goes together with knowledge of achievement. But that is clearly too strong: ' $S \phi$-ed intentionally' does not necessarily entail that $S$ knew of her success at the time. The same holds for any achievement along the way. In order to be compatible with our inference patterns, Anscombe's knowledge requirement would have to be read as containing the following claim: Even though for any specific ' $\phi^{*}$ ' the inference from ' $S \phi^{*}$ ed intentionally' to ' $S$ knows that $s h e^{*} \phi^{*}$-ed' is not necessarily valid, it still holds that $S$ is $\phi$-ing intentionally only if $S$ knows for some specific $\phi^{*}$ that $s h e^{*}$ has $\phi^{*}$-ed.

It is hard to see how that claim can be rendered intelligible as long as one holds on to the purported identity between judgment and action. For it implies that the agent's knowledge of her action in progress can be partial. This has no parallel in the self-consciousness of framing the judgment that $p$. This shows that knowledge of what one is doing differs in kind from one's knowledge of what one is going to do, what one intends to do or, for that matter, what one judges as to be done. The former is by doing, since it contains knowledge of what one has done. The latter isn't, because it doesn't, at least not 
necessarily so. For this reason it seems to me that excluding what I have done from the scope of practical knowledge and trying to assimilate it to self-consciousness of one's judgment about what is to be done are two versions of the same mistake.

The above difference between knowledge of judgment and knowledge of action is connected with a number of disanalogies between the 'I think' and the 'I do' that are obscured by the identity thesis. Among them is the one that is the source of Oedipus' calamity. In judging that this man on the road has it coming, Oedipus thought of the one who was his father that he had it coming. But that his father has it coming is another judgment, different from the one Oedipus framed. Killing that man, by contrast, was the same action as killing his father, just under a different description. His mistake was one of judgment: he would have never done it if only he had known that this man wasn't just a stranger. But the source of his calamity is the realization of his thoughts in action. For, once he realizes his mistake in judgment, he has already corrected it: he doesn't think of that man as a stranger anymore. But his deed he can't undo. He has to come to terms with what he has done and deal with its results.

The judgment that $p$ and the intentional act of $\phi$-ing are utterly different in their relation to time and their material circumstances. If all goes well, even my perceptual judgment remains present as a current act of mind that may be subject to correction long after the perception that provided the occasion and the material is in the past. The done deed isn't correctible, because action is realizing one's thought in the objective world. My action is only real movement or change in material reality insofar as it attracts infinitely many true descriptions that are not within the scope of my intention and my spontaneous or practical knowledge. For this reason, it is never fully transparent to me. In knowing it from within or in the perspective of practical knowledge as actual progress I am aware of a side of it that I can't know in that 
manner. That is the doubleness of the deed - or the doing, for that matter. In that sense it is true that actions have, as Kosman put it, "lives of their own which [...] transcend the intentions and plans of their authors."

Against the background of the contrast between the judgment that $p$ and the action of $\phi$-ing, the choice, decision or intention of which the latter is the realization appears like a peculiar hybrid. On the one hand, it seems to be a kind of judgment. On the other hand, it is impossible to correct it once it has been executed. Depending on which aspect one focuses, it will appear in the one or the other register. It is the same with respect to the issue of transparency. Velleman uses Oedipus' other tragic misdeed in order to suggest that the doubleness of the deed is already internal to the intention to do it: "Oedipus intended to marry Jocasta but not to marry his mother, even though those actions were one and the same. His intention thus contained a mistaken representation of the action he intended to perform." (Velleman, 1989, 94) That seems true in this case. "But a man," Anscombe says, “can want [...] a wife." (Anscombe, 2000, §36) Even before thinking he met the one, Oedipus may have decided to get married one day.

It is one of the peculiar features of Velleman's version of Futurism that the same could be said in this case. For his official explanation of why Oedipus' intention mis-represents the action is the thesis that as a "self-fulling expectation" the prior intention represents a concrete particular action in the future, just obscurely. To my mind this shows that rational agency never entered the picture in the first place. In the paradigmatic case, the intended end is universal or general and for this reason fully transparent to its subject. To use Aristotle's famous example: 'to procure a covering'. Mediated through the determination of means (making $a$ coat out of this material with these tools) the production process culminates in the realized end that is a fully determined 
particular: the completed action and its result, the product: this coat over here.

According to Normativism, all the stages of this transition from the fully transparent universal to a particular with a life of its own have to be identical to one and the same normative judgment about what is to be done. If there is a notion of judgment that allows this, then it has to be one that is utterly different from the normative judgment about what is to be believed. In either case, the analogy is not illuminating. It obscures the central point. Realizing one's ends is, as Hegel would put it, always literally an 'alienation' - an externalization of one's thoughts. This allows a rational or purposive order to be in the material - in the arrangement of stones that is a house, for instance. At the same time, it is the ground of the possibility of the kind of 'alienation' that was the calamity of Oedipus and in a different way of Marx's worker: not being able to recognize oneself in what one knows to be one's work or product.

\section{REFERENCES}

Anscombe, G.E.M. Intention. Cambridge Mass.: Harvard University Press, 2000. "Before and After". In Metaphysics and the Philosophy of Mind: Collected Philosophical Papers Vol III, Oxford: Basil Blackwell, pp. 180-195, 1981.

Aristotle, The Complete Works of Aristotle, ed. By Barnes J., Princeton: Princeton University Press, 1984.

Nicomachean Ethics, trans. By Broadie, S., Rowe, C., Oxford: Oxford University Press, 2002.

De Interpretatione. In Barnes (1984, Vol. I).

Physics. In Barnes (1984, Vol. I). 
Poetics. In Barnes (1984, Vol. II).

Bratman, M. Intentions, Plans and Practical Reason. Cambridge Mass.: Harvard University Press, 1987.

Castañeda, H.N. "'He': A Study in the Logic of SelfConsciousness". Ratio, 8, pp. 130-157, 1966.

Davidson, D. Essays on Actions and Events. Oxford: Oxford University Press, 1980.

"Agency". In R. Binkley, R. Brounaugh, A. Marras (ed.), Agent, Action, and Reason, University of Toronto Press, 1971. Repr. in D. Davidson (1980), pp. 43-61. "Intending". In Y. Yovel (ed.), Philosophy of History and Action, D. Reidel and The Agnes Press. 1978. Repr. in D. Davidson (1980), pp. 83-102.

"The Logical Form of Action Sentences". In N. Rescher (ed.), The Logic of Decision and Action, University of Pittsburgh Press, 1967. Repr. in D. Davidson (1980), pp. 105-148.

DONNELLAN, K. "Knowing What I'm Doing", Journal of Philosophy, Vol. 60, No. 40, pp. 401-409, 1963.

Falvey, K. "Knowledge in Intention”, Philosophical Studies, Vol. 99, pp. 21-44, 2000.

Ford, A., Hornsby, J., Stoutland, F. (ed.), Essays on Anscombe's Intention, Harvard University Press, Cambridge Mass. 2011.

"The Province of Human Agency", Noûs 52 (3), pp. 697-720, 2018.

GEACH, P.T. “On Beliefs About Oneself”. Analysis, 18 (1), pp. 23-24, 1957.

Kosman, A. "Acting: Drama as the Mimesis of Praxis". In Virtues of Thought: Essays on Plato and Aristotle, , 
Cambridge, Mass.: Harvard University Press, pp. 94118, 2014.

HaAse, M. "Knowing By Doing". In Hinshelwood, A., Gebbes A., Beings and Doings, Oxford University Press, forthcoming.

Lavin, D. "Must There Be Basic Action?", Noûs 47 (2), pp. 273-301, 2013.

MARCUS, E. "Practical Knowledge as Knowledge of a Normative Judgment", IN THIS VOLUME

Rational Causation. Cambridge Mass.: Harvard University Press, 2012.

MarX, K., ENGELS, F. Die Deutsche Ideologie, in: Karl Marx und Friedrich Engels Werke, Bd. 3, Berlin: Dietz Verlag. 1978.

MARX, K. Ökonomisch-philosophische Manuskripte, Suhrkamp Verlag, Frankfurt a.M. 2009.

MCDOWELL, J. "Some Remarks on Intention in Action", The Amberst Lecture in Philosophy, 6, pp. 1-18, 2011.

"How Receptive Knowledge Relates to Practical Knowledge", published in German as "Zum Verhältnis von rezeptivem und praktischem Wissen", Deutsche Zeitschrift für Philosophie, 3, pp. 387-401, 2013.

Moran, R. Authority and Estrangement, Princeton: Princeton University Press, 2001.

Parsons, T. Events in the Semantics of English: A Study in Subatomic Semantics, Cambridge, Mass.: MIT Press, 1990.

Paul, S. "How We Know What We're Doing”, Philosopher's Imprint, Vol. 9, No. 11, 2009. 
RÖDL, S. Self-Consciousness, Cambridge Mass.: Harvard University Press, 2007.

RYLE, G. The Concept of Mind, , Chicago: University of Chicago Press, 1984, 151

SCHWENKLER, J. "Understanding 'Practical Knowledge", Philosopher's Imprint, Vol. 15, No. 15, 2015.

SETIYA, K. "Explaining Action". In Rationalism Without Reasons, Princeton: Princeton University Press, pp. 2176, 2007.

"Practical Knowledge". Ethics, 118, pp. 388-409, 2008. "Knowing How", Proceedings of the Aristotelian Society, Vol. CXII, pp. 285-307, 2012.

"Anscombe on Practical Knowledge". In Practical Knowledge: Selected Essays, Oxford: Oxford University Press, pp. 156-168, 2016.

SIEGEL, S. "The Phenomenology of Efficacy", Philosophical Topics, Vol. 33, No. 1, 2005.

Sophocles, Oedipus Tyrannus, in: Theban Plays, Trans. by P. Meineck and P. Woodruff, Cambridge: Hackett Publishing Company, 2004.

STROUD, B. "Doing Something Intentionally and Knowing That You Are Doing It", Canadian Journal of Philosophy, 43 (1), pp. 1-12, 2013.

Thompson, M. "Naïve Action Theory". In Life and Action, Cambridge, Mass.: Harvard University Press, pp. 85146, 2008

"Anscombe's Intention and Practical Knowledge" in: Ford (2011), pp. 198-210.

Velleman, D. Practical Reflection, Princeton: Princeton University Press, 1989. 
The Possibility of Practical Reason, Oxford: Oxford University Press, 2000.

"Time for Action". In The Possibility of Practical Reason. Second Edition, Michigan: Maize Books, pp. 330-345, 2015.

(cc) BY

Manuscrito - Rev. Int. Fil. Campinas, v. 41, n. 4, pp. 195-253, Oct-Dec. 2018. 